\title{
Dos escalas de peces acondicionadas para ríos con fuerte sequía estival en la cuenca del río Guadalquivir
}

\author{
García R. ${ }^{* *}$, Almazán E.A. ${ }^{1}$ \\ ${ }^{1}$ Dpto. Ingeniería Forestal. E. T. S. I de Montes. Ciudad Universitaria s/n , 28040 Madrid. \\ *e-mail: ricardo.garcia@upm.es
}

\begin{abstract}
Resumen
En las escalas de peces situados en ríos españoles sometidos a fuertes sequías estivales en los que el caudal disminuye a exiguas cantidades o incluso desaparece por completo, se genera el problema de la imposibilidad de ascenso de los peces debido a desniveles excesivos entre el río y el primer estanque. En el presente trabajo se exponen soluciones a estos problemas generados en el funcionamiento de dos escalas proyectadas para dos azudes existentes en el Rio Guadiamar. Para solucionar el problema de un desnivel excesivo entre el vertedero de entrada del agua y el primer estanque debido a la mínima cuantía de los caudales, se ha diseñado vertederos particularizados para los cuatro primeros estanques y así conseguir una transición paulatina del nivel de aguas. Para que el desnivel de aguas existente entre el río y el primer estanque aguas abajo de la barrera esté dentro de valores admisibles, se construirá un pequeño dique-rastrillo de $10 \mathrm{~cm}$ de altura que actúa como vertedero regulador. Para solventar la segunda barrera se ha proyectado una escala de rápidos y remansos en la que se ha construido un estanque donde concurren los flujos procedentes de la propia escala y del canal de atracción y así concentrar un volumen y profundidad de agua suficiente para facilitar el salto del pez.
\end{abstract}

Palabras clave: Azud, estiaje en ríos, franqueabilidad de ríos, azud, rampa de piedras.

\section{Introducción}

Uno de los problemas ecológicos más importantes que presentan los ríos españoles consiste en la falta de permeabilidad por la existencia de barreras transversales (Nicola et al., 2001). Estas barreras impiden total o parcialmente el paso de los peces y de algunos macroinvertebrados.

En mayor o menor cuantía este problema está extendido en todo el mundo, por 
ello la fragmentación causada por presas y azudes es considerada como uno de los mayores impactos que ha creado el hombre sobre los peces migratorios en los sistemas de ríos (Lucas and Baras, 2001).

La fragmentación de los ríos ha producido en España que la población de peces como la lamprea (Petromyzom marinus), saboga (Alosa fallax), y peces de la familia mugilidae, tales como salmonete (Mullus marmatus), esturión (Acepinser sturio) o la anguila (Anguilla anguilla) se haya reducido entre un $50 \%$ y un $100 \%$ en áreas de diferentes ríos (Nicola et al., 1996).

Los peces ciprínidos son los más frecuentes en la península Ibérica (Doadrio, 2001). Aunque este grupo de peces son potamodromos, también pueden llegar a recorrer grandes distancias para completar su reproducción, así algunos peces ciprínidos pueden emigrar considerables distancias para reproducirse, alimentarse o tener refugio (Lucas and Frear 1997; Ovidio and Phillippart, 2002; Katapodis 2005)

Si bien en la mayor parte de los ríos la mejor solución para recuperar la franqueabilidad podría ser la demolición de esta presa, se entiende que esta solución es solo posible en contados casos dada la necesidad de mantener la función de la barrera, en su mayor parte obras hidráulicas. Por este motivo y ante la imposibilidad de solucionar el problema con la demolición de la barrera, se impone plantear otras soluciones que permitan el paso de los peces migradores tanto en sentido ascendente como en sentido descendente sabiendo que la solución será más óptima en tanto en cuanto el dispositivo o actuación llevado a cabo permita el paso a la mayor cantidad y tipo de biota.

Es posible realizar distintas actuaciones y/o construir dispositivos para conseguir la permeabilidad del río, tales como escalas de artesas, pasos naturalizados, ascensores etc. Los más utilizados tanto por su eficacia como por su versatilidad y economía son las escalas de artesas y los pasos naturalizados. El continuo declive de las poblaciones de muchas especies ha estimulado la construcción de las escalas de peces, las cuales están incrementando de manera importante la transitabilidad para los peces migradores en los ríos (Clay, 1995).

Numerosos ríos de las cuencas mediterráneas españolas tienen un régimen hidrológico caracterizados por un fuerte estiaje, este estiaje produce una importante disminución de caudal, esta situación provoca que las escalas o cualquier tipo de paso deben ser diseñadas para ser eficaces tanto para caudales bajos como para la caudales notoriamente más grandes porque de no ser así se produciría una disminución del número de días válidos para el paso de la fauna. Este problema se presenta en el tramo alto del río Guadiamar afluente del río Guadalquivir en la provincia de Sevilla (España).

\section{Objetivos}

Conseguir la efectividad de la escala de artesas sucesivas para valores de caudales desde muy pequeños hasta valores altos especialmente para los caudales existentes durante el periodo de reproducción. 


\section{Características de las barreras}

Las barreras que impiden el paso a la ictiofauna en la zona de estudio son debidas a los siguientes azudes:

1. Presa del Alisar. Es una presa de mampostería hidráulica ubicada en las coordenadas (ETR S89 Huso 29) UTM: X: 215 071; Y: 4172 798. La altura es de $4 \mathrm{~m}$, y la longitud es de $60 \mathrm{~m}$.

El perfil de la presa del Alisar se muestra en la siguiente Fig. 1.

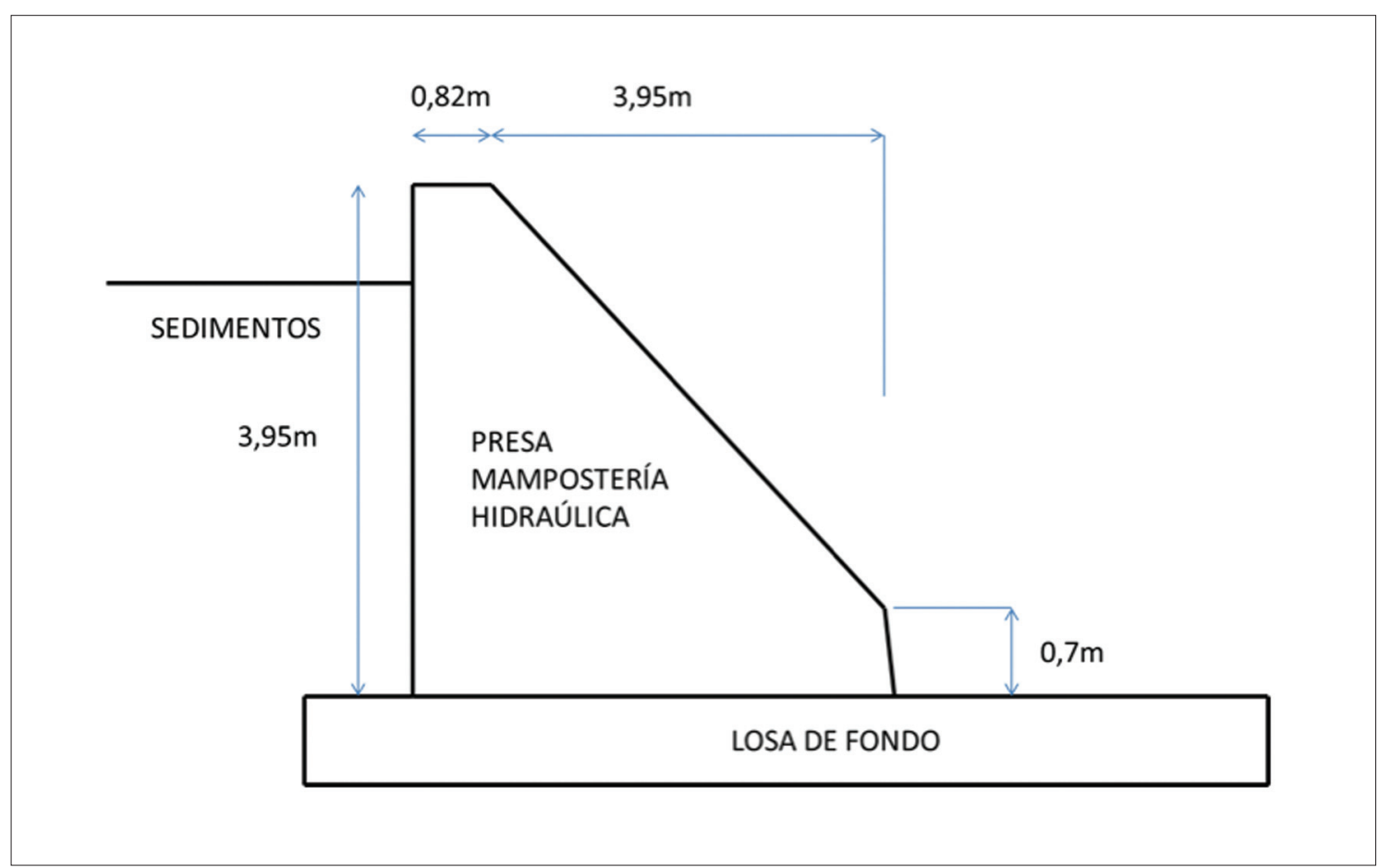

Figura 1. 1 Sección transversal del azud de Alisar.

2. Azud de Valdecargado. Se encuentran en la ubicación con las coordenadas (ETR S89 Huso 29) U.T.M. X 208 497, Y: 4117 827, la longitud es 48 metros. Uno de sus márgenes se encuentra deteriorado con una abertura de 2 ó 3 metros, siendo este el punto por donde vierte el agua. El desnivel del agua que se produce en la zona de rotura desde la lámina superior al nivel inferior del azud es aproximadamente de 1 metro. La sección transversal se muestra en la Fig. 2.

La estimación de los caudales se ha realizado a partir de dos fuentes de datos; la primera fuente corresponde a los datos proporcionados por la estación de Aforos de Gerena y el segundo origen de los datos es por el modelo hidrológico SIMPA. En la barrera del azud del Alisar se han utilizado caudales medios de la estación de Aforos de Gerena en el periodo comprendido entre los años 1983 y 2006 de los meses marzo, abril, mayo y junio. En la barrera del azud de Valdecargado se han uti- 


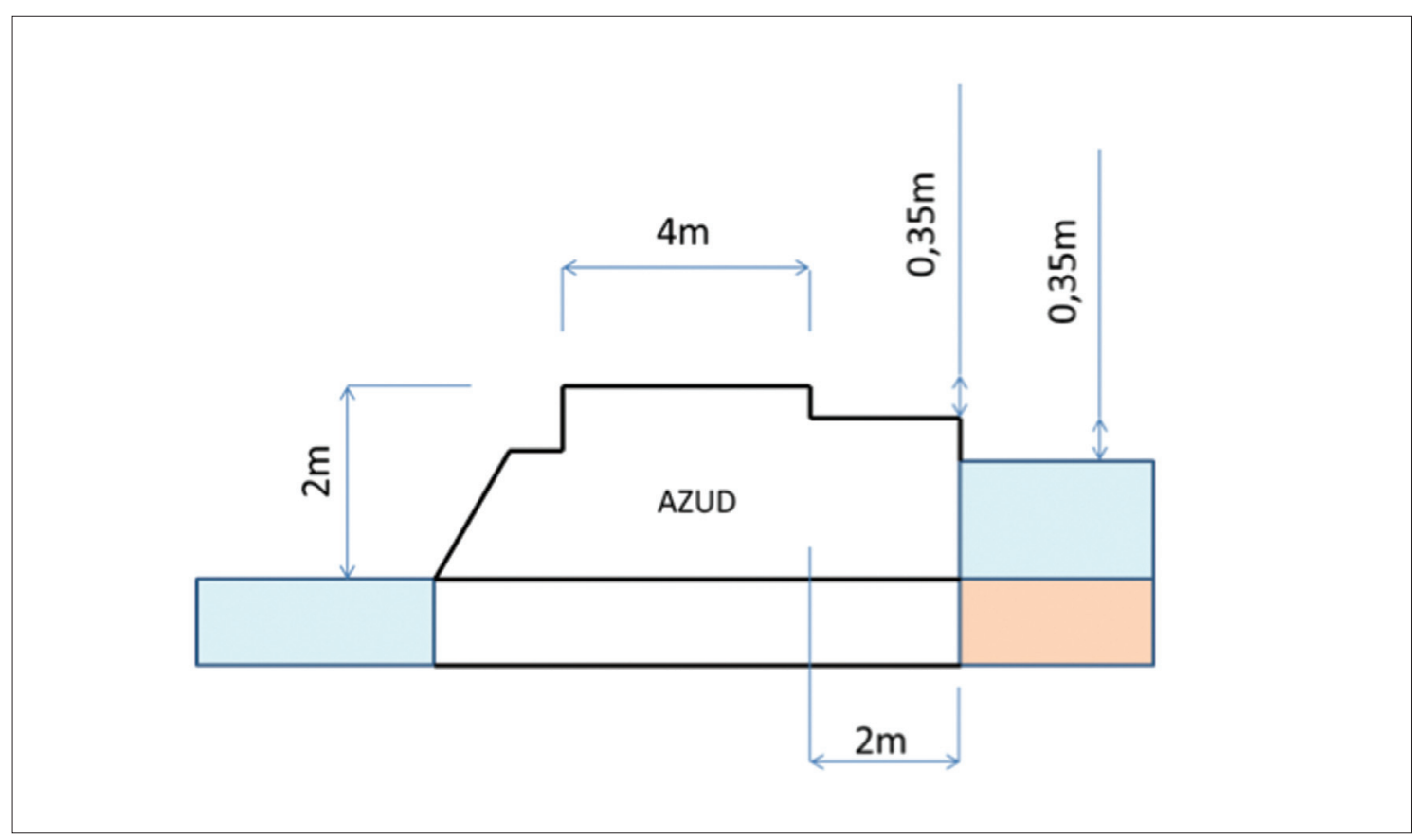

Figura 2. Sección transversal del azud de Valdecargado.

lizado los caudales mensuales del nudo SIMPA de código 3064 en el periodo comprendido entre el año 1940 hasta el año 2006.

En la Tab. 1 se expone los valores de los caudales. Para caracterizar dicho régimen según la clasificación de año húmedo, medio y seco, se ha empleado el software IAHRIS (Índice de Alteración Hidrológica en Ríos) desarrollado por la Escuela Técnica Universitaria de Ingenieros Forestales de la UPM.

Tal como puede verse en la Tab. 1, se puede apreciar una fuerte sequía durante los meses de primavera en los años caracterizados como medios en el periodo de años estudiados, dándose caudales de $0.219,0.427$ y $0.564 \mathrm{~m}^{3} \mathrm{~s}^{-1}$.

Según los inventarios realizados por la Junta de Andalucía, las especies ictícolas más importantes existentes en el tramo del río son el barbo gitano (Luciobarbus sclateri) y la boga de río (Pseudochondrostoma willkommi). Además se consideran dos especies autóctonas como especies potenciales en el caso de conseguir mejorar las condiciones ambientales del río; estas dos especies son la pardilla (Chondrostoma lemmingii) y el capitán (Mugil cephalus) (Blanco-Garrido, 2006).

\section{Resultados para la adaptación de las escalas a los caudales circulantes}

A) Presa del Alisar.

Para conseguir la franqueabilidad de los peces se propone la construcción de una escala de artesas sucesivas. Si bien desde un criterio medioambiental el tipo de paso más apropiado sería un paso naturalizado, en este caso en concreto se ha optado por 
Tabla 1. Caudales medios mensuales en $\mathrm{m}^{3} \mathrm{~s}^{-1}$ de la estación de aforo de Gerena con código 5056 obtenidos durante el periodo de años 1983-2006

\begin{tabular}{|c|c|c|c|}
\hline Mes & Año húmedo & Año medio & Año seco \\
\hline octubre & 0.948 & 0.021 & 0.000 \\
\hline noviembre & 3.120 & 0.168 & 0.015 \\
\hline diciembre & 4.814 & 1.388 & 0.086 \\
\hline enero & 6.881 & 1.798 & 0.171 \\
\hline febrero & 5.548 & 0.941 & 0.176 \\
\hline marzo & 3.409 & 0.564 & 0.136 \\
\hline abril & 3.873 & 0.427 & 0.057 \\
\hline mayo & 3.716 & 0.219 & 0.011 \\
\hline junio & 0.482 & 0.014 & 0.000 \\
\hline julio & 0.062 & 0.000 & 0.000 \\
\hline agosto & 0.053 & 0.000 & 0.000 \\
\hline septiembre & 0.080 & 0.000 & 0.000 \\
\hline
\end{tabular}

la escala de artesas por varias razones: si se quisiera realizar una rampa rústica u otro tipo de paso naturalizado debería hacerse en "by pass" por lo tanto debería de situarse en los márgenes del río, lo cual además de costoso, sería complicado, porque la obtención de la autorización para poder construir el paso o conseguir la propiedad de las mismas requiere de largos y costosos trámites. Además se debe considerar que dada la altura existente en el azud (cuatro metros), la longitud del posible paso naturalizado sería bastante grande lo cual implica mucha superficie disponible.

Por todo ello se ha optado por la escala de artesas sucesivas. Este tipo de escalas ha sido y sigue siendo la más utilizada; entre otras causas, porque presenta la ventaja de una gran adaptabilidad y la posibilidad de pliegue, lo cual permite utilizarla en circunstancias de escasa disponibilidad de suelo y/o con topografías complejas, por estas y otras razones esta escala se viene utilizando desde hace bastante tiempo. Actualmente el método de cálculo aplicado ha sido desarrollado por Larinier (1992, 2002). En la Fig. 3, se muestra la planta de la escala propuesta.

Las adaptaciones proyectadas a la escala para evitar los problemas generados por caudales muy pequeños debidos a la fuerte sequía, consisten en:

- Cota del vertedero de la entrada del agua a la escala a una altura inferior a la cota del vertedero de la presa.

- Modificaciones de los vertederos de los cuatro primeros estanques para garantizar que el desnivel de agua entre el último estanque y el vertedero de entrada del agua a la escala sea admisible por el pez.

- Aproximación del primer estanque de la escala al umbral del vertedero de la presa.

- Construcción de un vertedero autoregulador del desnivel de agua entre el primer estanque de la escala y el río, consiguiendo con este dispositivo valores mínimos de desniveles admisibles por los peces. 


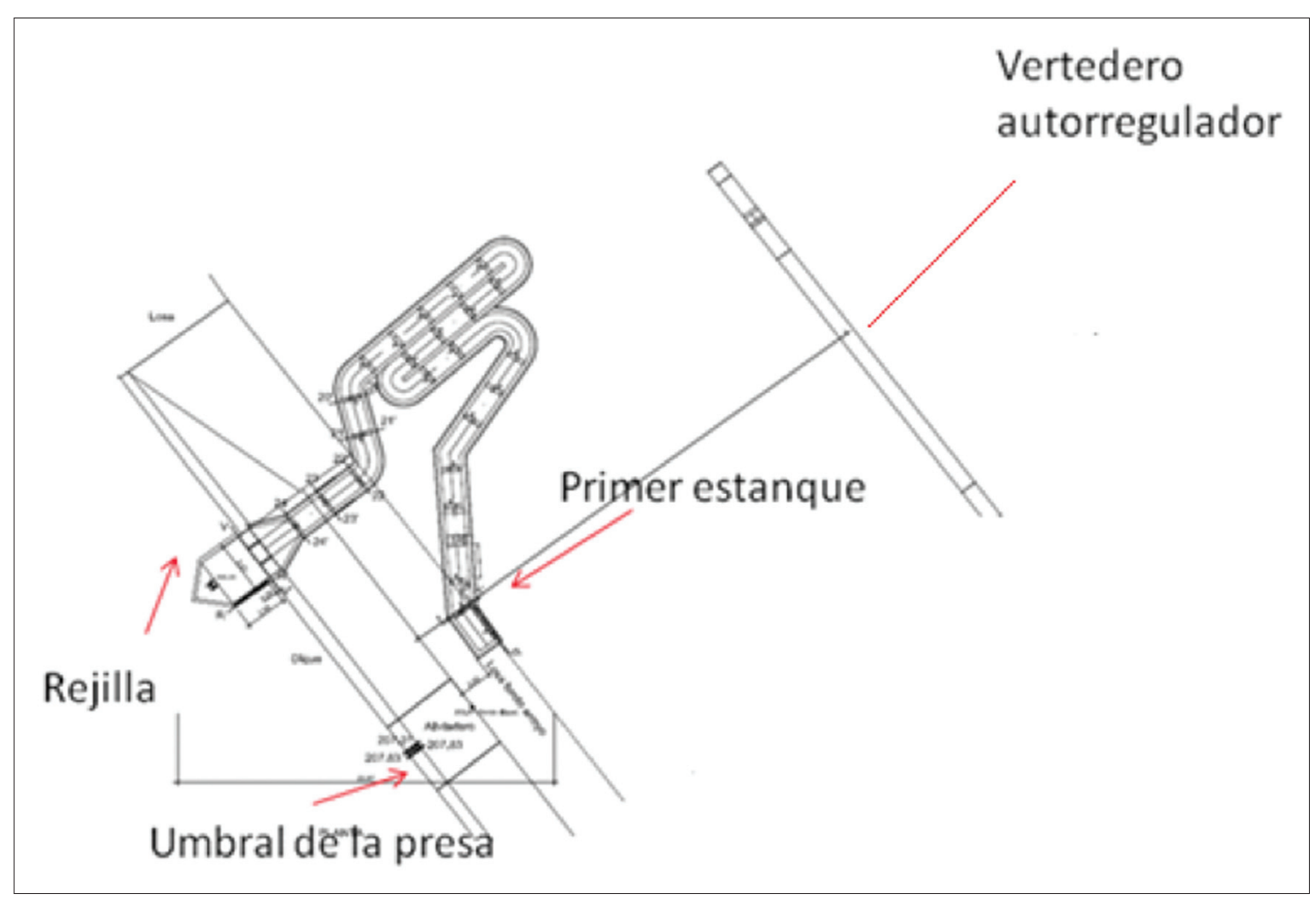

Figura 3. Planta de la escala para la presa del Alisar.

1. Cota del vertedero de entrada del agua por debajo del umbral de la presa. Situando la cota de la entrada del agua a nivel inferior del vertedero de la presa se consigue que todo el caudal circulante por el río entre en la escala, cuando los caudales son muy bajos (ver Fig. 5).

Se da la circunstancia de que al situar el vertedero de entrada por debajo de la cota del umbral de la presa implica que a medida que aumenta el caudal del río, también aumentará paulatinamente el caudal de entrada a la escala (evidentemente esta circunstancia ocurre siempre, si bien en este caso más acentuadamente), por este motivo con la finalidad de evacuar el exceso de caudal, se ha pensado que las paredes laterales de los dos primeros estanques sean a la vez vertedero laterales para que se produzca la salida del agua sobrante. Para ello las alturas de las paredes laterales de los dos primeros estanques se han proyectado de menor altura que las del resto de los estanques, si bien cuando el nivel del agua de entrada sea suficientemente alto, los caudales que entrarán son relativamente grandes, el estanque superior (primer estanque empezando por arriba) tiene dimensiones mayores que el resto de los estanques y ya en este estanque la mayor parte del caudal sobrante empieza a verterse por las paredes laterales, en el segundo estanque llegará poco caudal sobrante, que en cualquiera de los casos también desaguará por las paredes, por lo tanto en los dos casos, la energía disipada no excede sensiblemente a los valores admisibles. 
2. La aproximación del primer estanque al lugar por donde descenderá la lámina de agua tiene la finalidad de conseguir el efecto de "atracción" del pez para que se dirija al primer estanque. En esta escala en concreto, el mayor número de días los caudales serán pequeños, la mayor parte del caudal descenderá por la escala y por el vertedero de la presa situado en el centro, dado que este tiene menor cota que el resto del umbral, como los caudales se concentrarán en la parte central de la presa, será justamente en esta zona donde se dirijan los peces, por ello el primer estanque se ha ubicado en este lugar.

3. Adaptación de los vertederos de los estanques finales (21, 22, 23 y 24). Esta modificación de la sección tipo supone una innovación al método de cálculo habitual descrito por Larinier (1992).

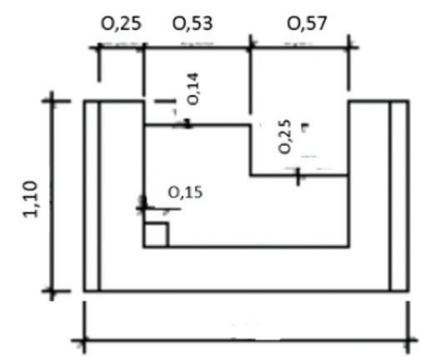

SECCIÓN 21-21'

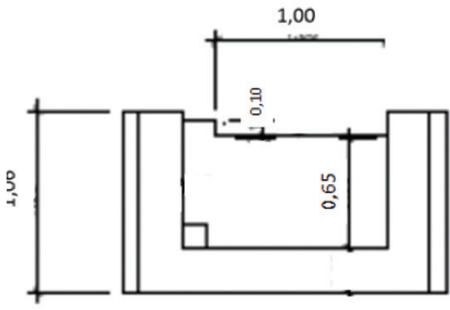

SECCIÓN 23-23'

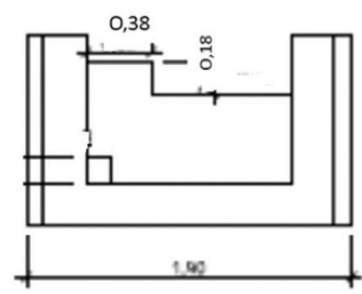

SECCIÓN 22-22'

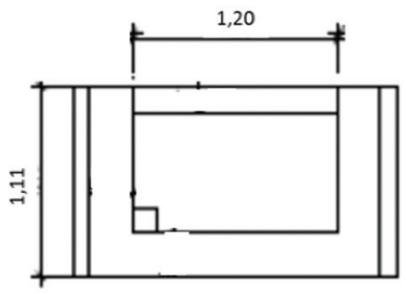

SECCIÓN 24-24'

Figura 4. Vertederos de los estanques 21, 22, 23 y 24.

Como se aprecia en la Fig. 4, los vertederos de los estanques de las secciones $21,22,23$ y 24 han sido modificados respecto al diseño convencional. Si se optase por el perfil convencional de escala de artesas sucesivas con vertedero semisumergido, en los periodos de caudales muy bajos, bastantes frecuentes en este río por existir una gran sequía, surgiría el problema de que se produciría un gran desnivel de altura entre la lámina de agua de la escotadura del dique por donde entra el agua a la escala y la lámina del agua del primer estanque, esta circunstancia sería debido a que la escotadura estaría a una considerable altura respecto al primer estanque, por lo tanto cuando se produce poco caudal, la altura de la lámina de agua del estanque superior sería muy baja. 
Se podría plantear como una posible solución aumentar el número de estanques para que el desnivel final entre la escotadura vertedero de entrada del agua a la escala y el primer estanque sea siempre menor; en este caso el problema surgirá con caudales medios o altos, porque éstos anegarían rápidamente el estanque que si bien el agua sobrante podría salir por las paredes laterales, el caudal que entraría en la escala sería muy pequeño porque la cota del umbral del vertedero lateral del primer estanque se concluyó que debía ser elevada para evitar el problema original surgido con la creación de desniveles altos cuando hubiera caudales mínimos.

Por todo ello la solución elegida ha sido diseñar el vertedero para cada estanque, con distintas alturas y longitudes para que la transición desde la escotadura totalmente rectangular hasta el perfil convencional sea de manera gradual y sobre todo valido para los muy distintos caudales existentes en el río.

Como se muestra en la figura 3, la sección 24 presenta un vertedero de gran longitud pero de altura pequeña, es decir el vertedero es toda la anchura del tabique, tal y como es el vertedero en la escotadura por donde entra el agua procedente del río. La sección 23 ha sido modificada respecto a la anterior aumentando la altura y disminuyendo la longitud, de esta forma paulatinamente se asemeja a la sección tipo de los vertederos laterales semisumergidos propios de este tipo de escala de artesas sucesivas. En las siguientes secciones, 22 y 21 la modificación continua el mismo criterio, con ello la sección se acerca paulatinamente al tipo convencional.

Como en los primeros cuatro estanques la altura del vertedero aumenta, a medida que se pasa de un estanque al siguiente, también aumenta la altura del desnivel del agua entre estanque y estanque, por este motivo en estos cuatro estanques superiores se ha disminuido la altura de desnivel entre estanque y estanque (no confundir con el desnivel de la altura entre los vertederos) para compensar el aumento de desnivel en la lámina vertiente producido por el aumento de la altura de los vertederos.

4. El vertedero autoregulador del nivel de agua, se ha situado aguas abajo de la escala, a la distancia de $32 \mathrm{~m}$. La ubicación se ha realizado en una sección del río donde existen las mejores condiciones para su construcción. El pequeño dique regulador presenta una sección compuesta acorde con la finalidad destinada, es decir mantener el desnivel entre el río y la lámina del primer estanque en los valores adecuados para que el pez pueda alcanzar el primer estanque sin dificultad; la altura de desnivel elegida es de $0.15 \mathrm{~m}$.

El cálculo para dimensionar el vertedero regulador se debe de realizar por medio de una hoja de cálculo, se debe tener en cuenta todo el caudal que atraviesa el río y el nivel que alcanza la lámina de agua para cada valor del caudal del río. El perfil que se adapta a estos requisitos se consigue con un perfil compuesto de varias alturas, de tal manera que cuando los caudales son bajos las longitudes de los vertederos son pequeñas y a medida que aumenta el caudal llega un momento en que por la escala circula el máximo cau- 
dal posible (como vimos anteriormente el resto es evacuado), entonces se dispone de longitudes de vertido más grandes para que no aumente excesivamente el nivel en el río ni tampoco debe crear un salto de agua por debajo del vertedero. La altura de este dique vertedero debe de ser muy pequeña, no debe sobrepasar $0.10 \mathrm{~m}$ respecto del lecho del río, porque de ser mayor podría provocar a su vez una nueva barrera. Para que no se produzcan fenómenos de erosión la anchura debe ser relativamente grande, superior a $1 \mathrm{~m}$. En la Fig. 5 se muestra el alzado del vertedero autoregulador.

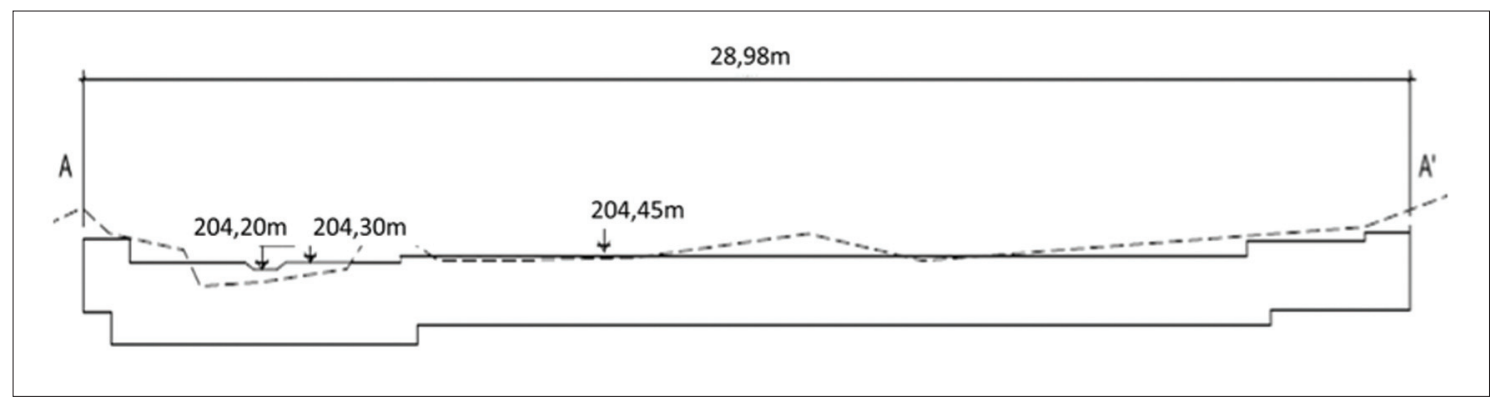

Figura 5. . Vertedero autoregulador.

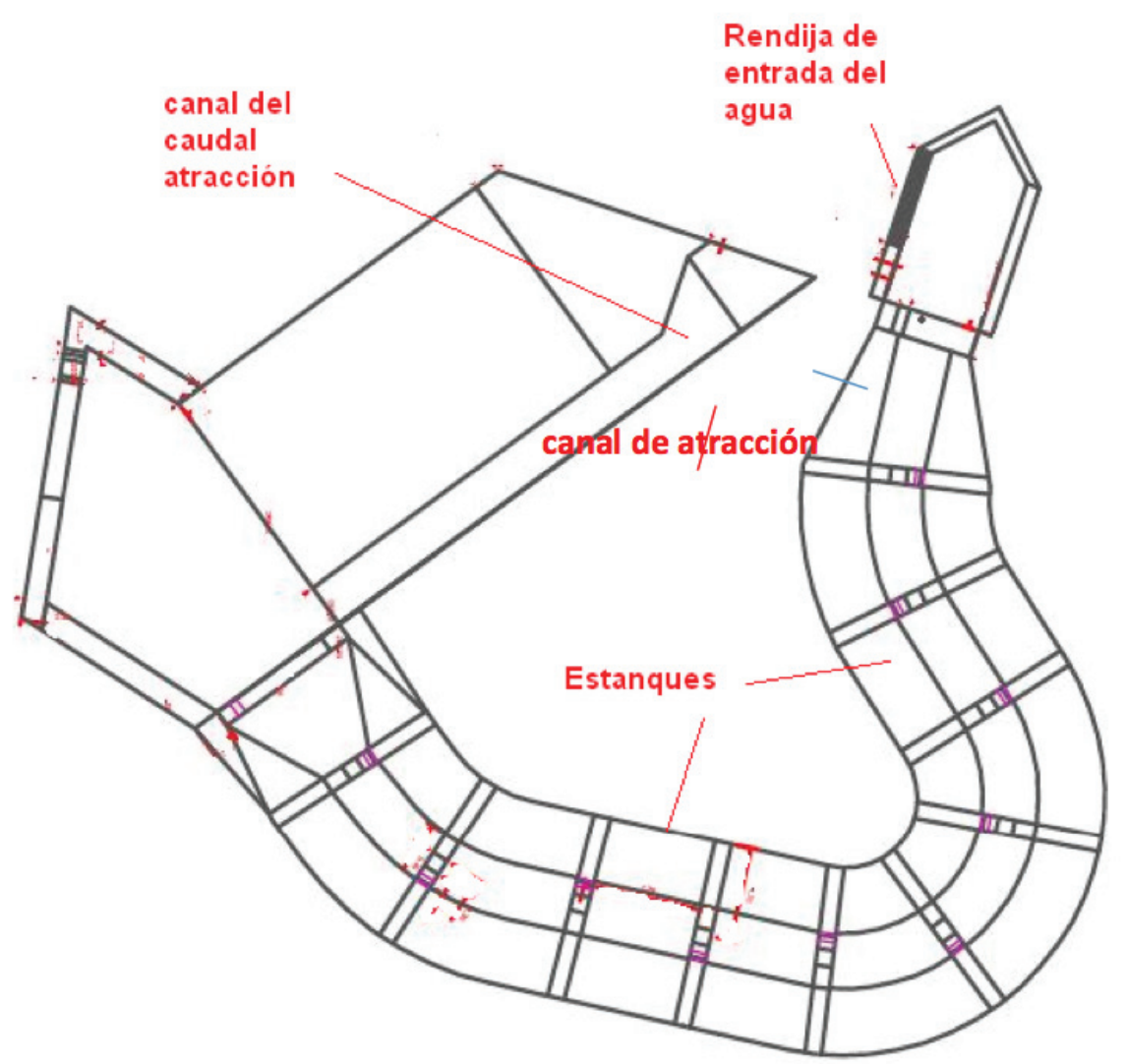

Figura 6. Plana de la escala del azud de Valdecargado. 
B) Azud del Valdecargado.

El azud de Valdecargado también está situado en el tramo superior del río Guadiamar. Se encuentra en un tramo del río por encima de la presa del Alisar, por consiguiente tiene menor caudal que el anterior. La escala diseñada podría considerarse como un paso naturalizado de rápidos y remansos, si bien tiene características similares a una escala de estanques sucesivos. La situación de la rampa con respecto al río es en la posición de "by pass" con respecto al curso principal. El material de construcción es de mampostería hidráulica

Las medidas adaptadas en esta escala debido a los pequeños caudales son:

1. Estanques muy pequeños, umbrales con distintos tipos de vertederos.

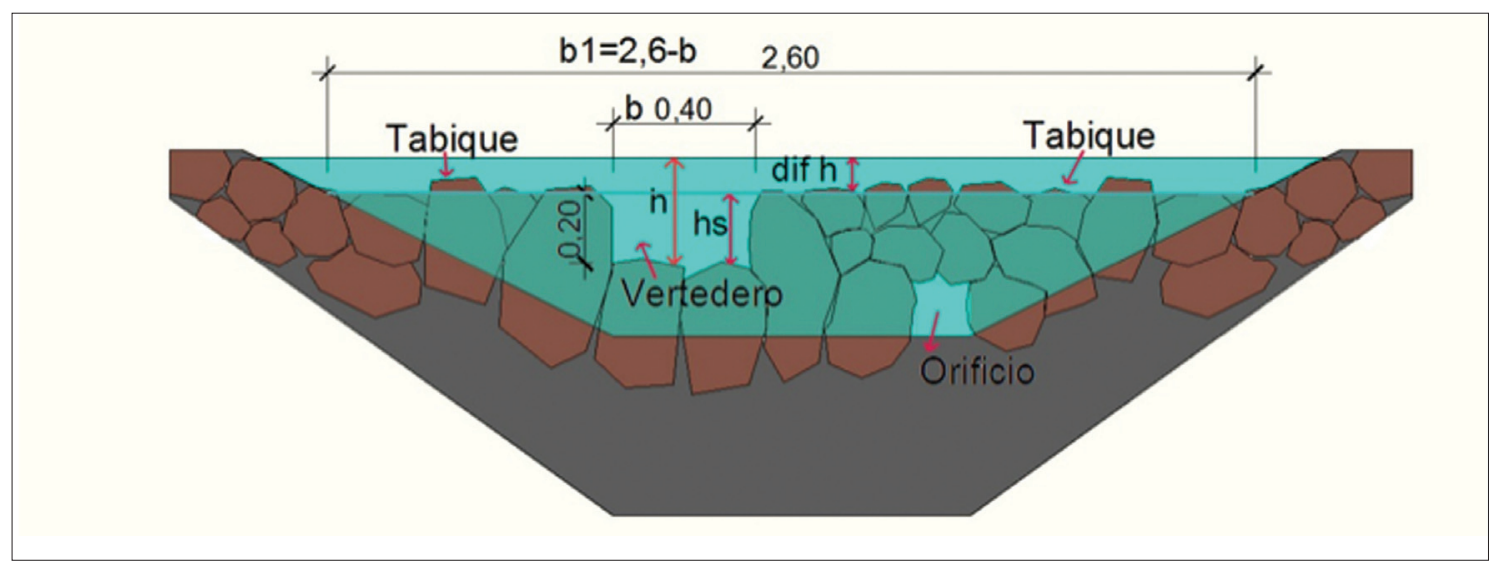

Figura 7. Sección transversal del umbral con vertederos.

En la Fig. 7 se muestra la sección transversal del umbral de uno de los estanques. Se aprecia que las dimensiones son pequeñas. Puesto que la escala debe funcionar con caudales muy bajos, la variación de caudales es grande por ello se propone que gran parte del tiempo el agua circule por encima de todo el umbral, de esta forma también se mejora la estética porque aumenta el aspecto de naturalización.

2. Vertedero de entrada. Por el mismos motivo que en la presa del Alisar, se ha dispuesto la entrada del agua a la escala a una cota inferior a la del vertedero del dique (ver Fig. 8).

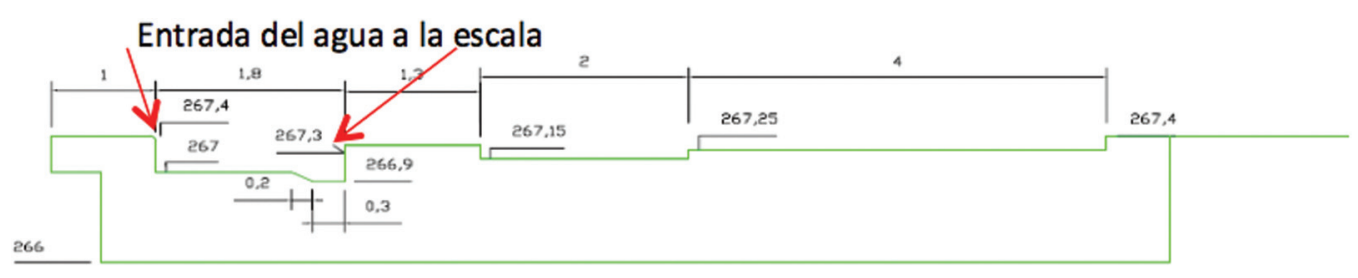

Figura 8. . Sección del vertedero de entrada del agua en la escala. 
3. Canalización del agua del vertedero del dique para su utilización como "caudal de atracción" (ver Fig. 6). El caudal medio que circula por este tramo es también pequeño, por ello se ha decidido construir una canalización que recoja toda el agua que atraviesa el vertedero del azud para su utilización como caudal de atracción.

4. Para poder controlar la diferencia de nivel entre el último estanque y el río se ha proyectado un depósito donde llegarán las aguas procedentes de la propia escala y de la canalización; la salida del agua de este depósito se realiza por medio de vertederos adecuados que controlen la altura del agua dentro del depósito para que el desnivel entre éste y el último estanque de la escala sea admisible para los peces migradores para todos los valores de los caudales circulantes.

\section{Conclusiones}

- En la escala de la presa del Alisar, se han modificado los vertederos de las secciones entre los estanque. La modificación se ha realizado de tal forma que el estanque a la entrada del agua tenga el vertedero semejante a la sección rectangular de la escotadura realizada en la presa, los vertederos de las secciones de los estanques siguientes se van asemejando a la sección tipo. Esta es una medida eficaz para mantener los desniveles entre estanques dentro de los valores admisibles.

- Con la construcción del vertedero regulador aguas abajo de la escala, en el caso de la escala de la presa del Alisar, se consigue controlar el desnivel del agua entre el primer estanque (por donde entra el pez) y el río. En el caso de la presa del Azud de Valdecargado la regulación se realiza con un depósito donde se concentran los flujos provenientes de la escala y de la canalización.

- Para conseguir que la escala tenga caudal en los días en que existan caudales muy pequeños se debe situar la entrada del agua a la escala por debajo de la cota del vertedero de la presa.

\section{Agradecimientos}

Los autores de esta comunicación agradecemos a D. Javier Serrano Aguilar como responsable de la Dirección General del Dominio Público Hidráulico de la Agencia Andaluza del Agua, el apoyo y la autorización de publicación de gran parte de datos y figuras presentes en este trabajo, también queremos manifestar nuestro agradecimiento a la empresa INCISA por ser la consultora privada colaboradora del proyecto base de este trabajo 


\section{Referencias}

Blanco-Garrido, F., 2006. Ecología, distribución y conservación de peces continentales en el cuadrante suroccidental ibérico. Tesis doctoral. Universidad de Huelva.

Clay, C. H., 1995. Design of fishways and other fish facilities, 2 end. Lewis Publisher, Boca Raton, FL. USA.

Doadrio, J., 2001. Atlas y libro rojo de los peces continentales de España. Museo Nacional de Ciencias Naturales, Madrid.

Katapodis, C., 2005. Developing a toolkit for fish passage, ecological flow management and fish habitat works. J. Hydr. Res. 43:451-467.

Larinier, M., 1992. Passes a bassins succesifs, prébarrages et riviéres artificielles. Bull. Fr. Pêche Pisci. 326/327, 73-94.

Larinier, M., 2002. Pool fishways, pre-barrages and natural bypass channels. Bull. Fr. Pêche Piscic. 364 suppl. pp 54-82.

Lucas, M. C., Baras, E.; 2001. Migration of freshwater fishes, Ed. Blackwell Science, Oxford, UK.

Nicola, G.G., Elvira, B., Almodovar, A.; 1996. Dams and fish passage facilities in the large rivers of Spain: effects on migratory species. Arch. Hydrobiol. Suppl. 113 375-379 pp Sttugart.

Ovidio, M., Phillippart, J.C., 2002. The impact of small physical upstream movement of six species of fish- Synthesis of a 5-year telemetry study in the river Meuse basin. Hydrobiologia 483:55-69. 